\title{
The Epidemiology of Herpes Zoster and Postherpetic Neuralgia in China: Results from a Cross-Sectional Study
}

Fei Yang - Shengyuan Yu • Bifa Fan · Yanqing Liu - Yu Xuan Chen ·

Ian Kudel · Kristen Concialdi · Marco DiBonaventura •

Markay Hopps · Patrick Hlavacek · Joseph C. Cappelleri ·

Alesia Sadosky $\cdot$ Bruce Parsons · Margarita Udall

Received: February 28, 2019 / Published online: June 19, 2019

(C) The Author(s) 2019

\section{ABSTRACT}

Introduction: Few studies have examined the epidemiology of herpes zoster (HZ) and postherpetic neuralgia (PHN) in China. The aim of this study was to estimate the prevalence of $\mathrm{HZ}$ and PHN in China, and to examine the clinical characteristics of patients identified with PHN.

Methods: This was a cross-sectional study conducted in 24 hospitals in seven cities in China. Prevalence of HZ and PHN was determined by physician $(n=100)$ chart review of patients ( $n=36,170)$ aged $\geq 40$ years seeking medical care over a 30 - to 60 -day period. The health history of patients identified with PHN was

Enhanced Digital Features To view enhanced digital features for this article go to https://doi.org/10.6084/ m9.figshare.8174918.

F. Yang $\cdot$ S. Yu $(\bowtie)$

Department of Neurology, Chinese PLA General

Hospital, Hai Dian District, Beijing, China

e-mail: yusy1963@126.com

B. Fan

Department of Pain Medicine, Pain Management

Center, China-Japan Friendship Hospital, Chao

Yang District, Beijing, China

Y. Liu

Pain Department Center, Beijing Tian Tan Hospital, Dong Cheng District, Beijing, China

Y. X. Chen

Pfizer China, Beijing, China obtained and included time since diagnosis of $\mathrm{HZ}$ or PHN, time since onset of PHN-related pain, and the methods used for diagnosing $\mathrm{HZ}$ and PHN.

Results: The prevalence rates of $\mathrm{HZ}$ and $\mathrm{PHN}$ were $7.7 \% \quad[95 \%$ confidence interval (CI) 7.5-8.0] and 2.3\% (95\% CI 2.2-2.5), respectively. Of patients with $\mathrm{HZ}, 29.8 \%$ developed PHN. Rates of HZ and PHN increased with age and were highest in patients aged $\geq 70$ years (10.6\% and $4.1 \%$, respectively). The majority of patients with $\mathrm{PHN}$ were diagnosed with $\mathrm{HZ}$ (80.9\%) and PHN (83.8\%) for $<1$ year, and had experienced PHN-related pain for $<1$ year (80.5\%). Patient description and clinical examination were most commonly used to diagnose $\mathrm{HZ}$ and PHN.

Conclusion: These results provide current estimates of the prevalence of $\mathrm{HZ}$ and PHN in the

\author{
I. Kudel · K. Concialdi \\ Kantar Health, New York, NY, USA \\ M. DiBonaventura · M. Hopps · P. Hlavacek · \\ A. Sadosky · B. Parsons · M. Udall \\ Pfizer Inc, New York, NY, USA \\ J. C. Cappelleri \\ Pfizer Inc, Groton, CT, USA \\ Present Address: \\ Y. X. Chen \\ Capital Medical University, Beijing, China
}


general adult population in urban China. These rates are similar to previously reported rates in China and worldwide, and highlight the global nature of $\mathrm{HZ}$ and PHN.

Funding: Pfizer Inc.

Keywords: Chronic pain; Comorbidities; Epidemiology; Herpes zoster; Neuropathic pain; Neuropathy; Postherpetic neuralgia; Prevalence

\section{INTRODUCTION}

Herpes zoster (HZ) is caused by reactivation of the varicella-zoster virus from a latent state and is usually characterized by a unilateral, acutely painful vesicular rash that affects a single dermatome and is self-limiting, typically resolving in a few weeks $[1,2]$. Postherpetic neuralgia (PHN) is a common clinical complication of $\mathrm{HZ}$ that presents as severe, often persistent, pain that occurs after the rash has resolved $[1,2]$. The risk of developing $\mathrm{PHN}$ in patients with $\mathrm{HZ}$ varies from 5\% to more than $30 \%$, as recently reported in a systematic review of 130 studies in 26 countries [3]. The occurrence of both $\mathrm{HZ}$ and PHN increases with age $[3,4]$, and incidence rates appear to be increasing over time [3].

Most epidemiological studies have been conducted in North America and Europe, and have indicated a global incidence rate of $\mathrm{HZ}$ of approximately 3-5/1000 person-years [3, 5-7]. In the Asia-Pacific region, incidence of approximately 3-10/1000 person-years [8] has been reported across Australia [9], Taiwan [10-12], South Korea [13, 14], and Japan [15]. The risk of developing $\mathrm{PHN}$ in patients with $\mathrm{HZ}$ ranges from $6.2 \%$ to $52.0 \%$ in the Asia-Pacific region [8], including across Australia [9], Taiwan $[10,16]$, South Korea [17], Japan [18, 19], Thailand [20, 21], Singapore [22], and India $[23,24]$. Few epidemiological investigations of $\mathrm{HZ}$ and PHN have been conducted in China. In a multistage sampling, cross-sectional study of 7149 rural and urban adults aged $\geq 50$ years from across Guangdong province, a lifetime prevalence of $\mathrm{HZ}$ of $3.5 \%$ was reported [25]. Additionally, the lifetime prevalence of $\mathrm{HZ}$ was higher in women than in men, and increased with age. In patients with $\mathrm{HZ}$, the incidence rate of PHN, defined as pain lasting $\geq 1$ month after the rash has healed, was $40.2 \%$. In a separate community-based retrospective study of 49,721 rural and urban Chinese adults aged $\geq 50$ years, the average annual incidence rate of $\mathrm{HZ}$ was $3.4 / 1000$ person-years [26]. The average annual incidence rate was higher in women than in men and increased with age. Rates were higher in the urban population than in the rural population. A community-based retrospective survey in selected districts of Beijing reported an annual incidence rate of $\mathrm{HZ}$ of 1.9/1000 personyears, with higher rates in women $(2.4 / 1000$ person-years) than in men $(1.7 / 1000$ personyears) [27]. In a separate study of 522 patients with HZ, including some patients aged $<20$ years, PHN was identified in $6.9 \%$ of patients [28].

The main objective of this study was to determine the prevalence of $\mathrm{HZ}$ and $\mathrm{PHN}$ in patients seeking medical care in urban China. The secondary objective was to describe the clinical characteristics of those patients with PHN.

\section{METHODS}

\section{Study Design}

This cross-sectional epidemiological study was conducted between August and December 2016 at hospital sites in Tier 1 and Tier 2 cities in China. China has over 600 cities that are often categorized in different tiers based on criteria such as population size, resident average income, and development of services or infrastructure. Tier 1 cities represent the most developed areas, and Tier 5 the less developed smaller cities. This study was conducted in accordance with legal and regulatory requirements and accepted research practices described in the Good Practices for Outcomes Research issued by the International Society for Pharmacoeconomics and Outcomes Research [29, 30]. The final protocol and any amendments were reviewed and approved by the ethics committee at Chinese PLA General Hospital, Hai Dian District, Beijing. As this was a retrospective 
epidemiological study, patient consent was not required.

The study consisted of two phases. In Phase 1, participating physicians reviewed the charts of patients aged $\geq 40$ years who visited their office seeking medical care over the course of 30-60 days, and the presence or absence of HZ and/or PHN in each patient was documented. Inclusion criteria for physicians were a specialty in dermatology, neurology, and/or pain, and seeing a minimum of 200 patients aged $\geq 40$ years over a 2 -month period. In total, 100 physicians at 24 hospital sites across Tier 1 and Tier 2 cities participated. Participating hospitals were geographically dispersed across China and were all Tier 3 hospitals. The specific city locations were Guangzhou, Shenzhen, Beijing, Shanghai, Nanjing, Xi'an, and Chengdu. During Phase 1, the records of 36,170 patients were reviewed. In Phase 2, physicians conducted a chart review using paper data collection forms of those patients identified with PHN in Phase 1, to assess health history.

\section{Assessment of Herpes Zoster and Postherpetic Neuralgia Prevalence}

PHN was defined as pain persisting for $\geq 1$ month following healing of the $\mathrm{HZ}$ rash [31]. The prevalence of $\mathrm{HZ}$ and $\mathrm{PHN}$ were determined by dividing the number of patients with each condition by the number of patients in the sample. The 95\% confidence intervals (CIs) were also derived. Analysis was conducted within gender and age groups (40-50, 51-59, $60-69$, and $\geq 70$ years) for each condition.

\section{Clinical Characteristics of Patients with Postherpetic Neuralgia}

During Phase 2, the physician chart review of health history determined the clinical characteristics of patients with PHN identified during Phase 1 . These clinical characteristics are listed in Table 1.
Table 1 Clinical characteristics used to determine the health history of patients with postherpetic neuralgia

\begin{tabular}{|c|c|}
\hline Characteristic & Additional information \\
\hline $\begin{array}{l}\text { Time since diagnosis of } \mathrm{HZ} \\
\text { or PHN }\end{array}$ & In years \\
\hline $\begin{array}{l}\text { Time since onset of pain } \\
\text { due to PHN }\end{array}$ & In years \\
\hline $\begin{array}{l}\text { Specialty of the physician } \\
\text { who diagnosed } \mathrm{HZ} \text { or } \\
\text { PHN }\end{array}$ & $\begin{array}{l}\text { Dermatologist } \\
\text { Neurologist } \\
\text { Pain specialist } \\
\text { Other }\end{array}$ \\
\hline $\begin{array}{l}\text { How each patient was } \\
\text { diagnosed with } \mathrm{HZ} \text { or } \\
\text { PHN }\end{array}$ & $\begin{array}{l}\text { By reporting physician } \\
\text { Referred to reporting } \\
\text { physician by another } \\
\text { physician at the same site } \\
\text { without diagnosis } \\
\text { Referred to reporting } \\
\text { physician by another } \\
\text { physician at the same site } \\
\text { with diagnosis } \\
\text { Referred to reporting } \\
\text { physician by another } \\
\text { physician at a different site } \\
\text { without diagnosis } \\
\text { Referred to reporting } \\
\text { physician by another } \\
\text { physician at a different site } \\
\text { with diagnosis }\end{array}$ \\
\hline $\begin{array}{l}\text { Method(s) used to diagnose } \\
\text { HZ or PHN }\end{array}$ & $\begin{array}{l}\text { Patient description } \\
\text { Clinical exam } \\
\text { Other }\end{array}$ \\
\hline $\begin{array}{l}\text { How the patient presented } \\
\text { with rash and pain }\end{array}$ & $\begin{array}{l}\text { Rash first followed by pain } \\
\text { Pain first followed by rash } \\
\text { Pain and rash at the same } \\
\text { time } \\
\text { Not reported }\end{array}$ \\
\hline
\end{tabular}


Table 1 continued

\begin{tabular}{ll}
\hline Characteristic & Additional information \\
\hline $\begin{array}{l}\text { Length of time between } \\
\text { presentation of rash and }\end{array}$ & In years \\
occurrence of pain, or & \\
between presentation of & \\
pain and occurrence of & \\
rash & \\
Type of previously & Occurring in $\geq 10 \%$ of \\
diagnosed comorbidities & patients \\
\hline
\end{tabular}

$H Z$ herpes zoster, $P H N$ postherpetic neuralgia

\section{Statistical Methods}

Descriptive statistics are provided, specifically counts, percentages, and sample size; 95\% CIs were determined where applicable. No statistical comparisons between groups were made. All available data are reported, with no imputation strategy for missing data.

\section{RESULTS}

\section{Patient Sample}

The majority of the 36,170 patients who were reviewed during Phase 1 were female $(n=19,204$, $53.1 \%)$. Patients were evenly split across age groups ( $40-50$ years: $n=10,186,28.2 \%$; 51-59 years: $n=8885, \quad 24.6 \% ; \quad 60-69$ years: $n=8770,24.2 \%$; $\geq 70$ years: $n=8329,23.0 \%$ ). For Phase 2, the clinical characteristics of 828 patients with PHN from seven hospital sites were assessed.

\section{Estimated Prevalence of Herpes Zoster}

In total, 2803 patients were identified with HZ. The overall estimated prevalence of $\mathrm{HZ}$ was $7.7 \%$ (Table 2). Women had a slightly higher prevalence rate than men $(7.9 \%$ vs. $7.6 \%)$. Prevalence rates increased with age. The lowest rate by age group was in those aged 40-50 years $(5.5 \%)$ and the highest was in those aged $\geq 70$ years $(10.6 \%)$.
Table 2 Estimated prevalence rates of herpes zoster overall, and by gender and age group

\begin{tabular}{ccccc}
\hline & $\begin{array}{l}\text { Total } \\
\text { number } \\
\text { of } \\
\text { patients }\end{array}$ & $\begin{array}{l}\text { Number } \\
\text { of } \\
\text { patients } \\
\text { with HZ }\end{array}$ & $\begin{array}{l}\text { Prevalence } \\
(\%)\end{array}$ & 95\% CI \\
\hline Overall & 36,170 & 2803 & 7.7 & $7.5-8.0$ \\
Gender & & & & \\
Male & 16,966 & 1294 & 7.6 & $7.2-8.0$ \\
Female & 19,204 & 1509 & 7.9 & $7.5-8.2$ \\
Age group, years & & & \\
$40-50$ & 10,186 & 562 & 5.5 & $5.1-6.0$ \\
$51-59$ & 8885 & 627 & 7.1 & $6.5-7.6$ \\
$60-69$ & 8770 & 733 & 8.4 & $7.8-8.9$ \\
$\geq 70$ & 8329 & 881 & 10.6 & $9.9-11.2$ \\
\hline
\end{tabular}

$C I$ confidence interval, $H Z$ herpes zoster

\section{Estimated Prevalence of Postherpetic Neuralgia}

Of the 2803 patients with HZ, 835 (29.8\%) had PHN. The overall estimated prevalence of PHN was $2.3 \%$ (Table 3 ). Men had a slightly higher prevalence rate than women $(2.4 \%$ vs. $2.2 \%)$. Prevalence rates increased with age. The lowest rate by age group was in those aged $40-50$ years $(1.0 \%)$ and the highest in those aged $\geq 70$ years (4.1\%). The prevalence rate by city ranged from $1.5 \%$ in Shanghai to $3.0 \%$ in Beijing (Table 3 ).

\section{Clinical Characteristics of Patients Diagnosed with Postherpetic Neuralgia}

The clinical characteristics of patients diagnosed with PHN are shown in Table 4. Of those patients who were later diagnosed with PHN, the majority were diagnosed with $\mathrm{HZ}$ for $<1$ year $(80.9 \%)$, with only a small proportion having been diagnosed with $\mathrm{HZ}$ for $\geq 5$ years $(3.3 \%)$. Dermatologists diagnosed HZ most often (78.7\%), followed by neurologists (11.9\%). A substantial number of patients were referred to the reporting physician from an outside hospital with an existing diagnosis of 
Table 3 Estimated prevalence rates of postherpetic neuralgia overall, and by gender, age group and city

\begin{tabular}{lllll}
\hline & Total number of patients & Number of patients with PHN & Prevalence (\%) & 95\% CI \\
\hline Overall & 36,170 & 835 & 2.3 & $2.2-2.5$ \\
Gender & & & & \\
Male & 16,966 & 407 & 2.4 & $2.2-2.6$ \\
Female & 19,204 & 428 & 2.2 & $2.0-2.4$ \\
Age group, years & & & & \\
$40-50$ & 10,186 & 102 & 1.0 & $0.8-1.2$ \\
$51-59$ & 8885 & 179 & 2.0 & $1.7-2.3$ \\
$60-69$ & 8770 & 215 & 2.5 & $2.1-2.8$ \\
$\geq 70$ & 339 & 4.1 & $3.7-4.5$ \\
City & 8329 & & & NA \\
Guangzhou & 8441 & 203 & 2.4 & \\
Shenzhen & 1402 & 28 & 2.0 & \\
Beijing & 6665 & 198 & 3.0 & \\
Shanghai & 3418 & 51 & 1.5 & \\
Nanjing & 6794 & 190 & 2.8 & \\
Xian & 5249 & 89 & 1.7 & \\
Chengdu & 4201 & 76 & 1.8 & \\
\hline
\end{tabular}

$C I$ confidence interval, $N A$ not available, $P H N$ postherpetic neuralgia

HZ (38.0\%). Patient description and clinical exam were most commonly used to diagnose $\mathrm{HZ}$, and most patients were diagnosed using a combination of both.

The majority of patients were diagnosed with PHN for $<1$ year $(83.8 \%)$, with a small proportion having been diagnosed with PHN for $\geq 5$ years $(2.7 \%)$. Similarly, most patients had PHN-related pain for $<1$ year $(80.5 \%)$, with only a small proportion having PHN-related pain for $\geq 5$ years $(4.3 \%)$. Dermatologists diagnosed PHN most often (49.5\%), followed by pain specialists $(28.9 \%)$ and then neurologists (18.4\%). The reporting physician most commonly diagnosed PHN (46.1\%), followed by referral to the reporting physician from outside the hospital with an existing diagnosis (24.6\%). PHN was most commonly diagnosed by a combination of patient description and clinical examination. Similar proportions of patients experienced a rash followed by pain (34.5\%), prodromal HZ pain followed by a rash (31.6\%), or rash and pain at the same time $(29.5 \%)$. The mean length of time between presentation of rash and occurrence of pain, or presentation of pain and occurrence of rash, was $<1$ year.

Of patients with $\mathrm{PHN}, 76.7 \%$ had comorbidities. Hypertension (35.7\%), type 1 or type 2 diabetes $(18.1 \%)$, osteoporosis (10.9\%), and high cholesterol $(10.0 \%)$ were the most common comorbidities.

\section{DISCUSSION}

Our findings show that among patients seeking medical help at hospital sites in urban China, the estimated prevalence of $\mathrm{HZ}$ is $7.7 \%$ and the estimated prevalence of $\mathrm{PHN}$ is $2.3 \%$. The estimated prevalence of $\mathrm{PHN}$ in patients with $\mathrm{HZ}$ 
was $29.8 \%$. HZ was slightly higher in women and PHN slightly higher in men. The prevalence of $\mathrm{HZ}$ and PHN increased with age, so that the highest prevalence of both occurred in patients aged $\geq 70$ years. Most patients had HZ and PHN for $<1$ year. Of those with PHN, most had PHNrelated pain for $<1$ year. Dermatologists most commonly diagnosed both $\mathrm{HZ}$ and PHN using a combination of patient description and clinical examination. Comorbidities were present in approximately three-quarters of patients with PHN.

The estimated overall prevalence of $\mathrm{HZ}$ reported here $(7.7 \%)$ is higher than the lifetime prevalence of $\mathrm{HZ}$ reported in a 2015 crosssectional study in Guangdong province (3.5\%) [25]. However, a higher prevalence in women and increasing prevalence with increasing age was a common finding in both studies, and is in agreement with a separate study in a mixed rural and urban Chinese population [26]. The estimated prevalence of PHN in the current study was $2.3 \%$. There have been no published surveys or previous estimates on the prevalence of PHN in China based on population. However, in the previous epidemiological study of $\mathrm{HZ}$ and $\mathrm{PHN}$ in Guangdong province, $40.2 \%$ of patients with $\mathrm{HZ}$ were reported as having PHN [25]. This is higher than the $29.8 \%$ of $\mathrm{HZ}$ patients with PHN reported here, even though the definition of PHN was the same (pain persisting for $\geq 1$ month). This difference may be explained by the methodological differences between the two studies. For instance, in the study by Zhu et al. [25], the patient sample was older ( $\geq 50$ years vs. $\geq 40$ years in the present study), and prevalence was based on patient recall rather than physician review of patient charts as in the current study. The study by Zhu et al. was also in a mixed rural/urban population, whereas the current study was in an urban population. A separate study identified PHN occurring in $6.9 \%$ of patients with $\mathrm{HZ}$ [28], which is considerably lower than that reported here. The figure reported here does agree with a recent systematic review of $\mathrm{HZ}$ and $\mathrm{PHN}$ epidemiology across the Asia-Pacific region, which reported reported between $\leq 10 \%$ and $\geq 25 \%$ of patients with $\mathrm{HZ}$ also had PHN [8]. However, as those authors noted, reported rates varied
Table 4 Clinical characteristics of patients diagnosed with postherpetic neuralgia

\begin{tabular}{ll}
\hline Clinical characteristic & Patients diagnosed \\
& with PHN $(n=828)$
\end{tabular}

Time since $\mathrm{HZ}$ diagnosis, $n(\%)$

$$
\begin{array}{lc}
<1 \text { year } & 670(80.9) \\
1 \text { year to }<5 \text { years } & 129(15.6) \\
\geq 5 \text { years } & 27(3.3)
\end{array}
$$

Specialty of physician who

diagnosed HZ, $n(\%)^{a}$

Dermatologist

Neurologist

Pain specialist

Other

How patient was diagnosed with $\mathrm{HZ}, n(\%)$

Diagnosed by reporting $234(28.3)$ physician

Referred to reporting physician from within hospital without diagnosis

Referred to reporting physician from within hospital with diagnosis already

Referred to reporting physician from an outside hospital without diagnosis

Referred to reporting physician from an outside hospital with diagnosis already

Method used for diagnosing

$\mathrm{HZ}, n(\%)$

Patient description

709 (85.6)

Clinical examination

Other

Time since PHN diagnosis,

$$
\begin{aligned}
& n(\%) \\
& <1 \text { year }
\end{aligned}
$$


Table 4 continued

\begin{tabular}{|c|c|}
\hline Clinical characteristic & $\begin{array}{l}\text { Patients diagnosed } \\
\text { with PHN }(n=828)\end{array}$ \\
\hline 1 year to $<5$ years & $110(13.3)$ \\
\hline$\geq 5$ years & $22(2.7)$ \\
\hline \multicolumn{2}{|l|}{$\begin{array}{l}\text { Time since onset of pain due to } \\
\text { PHN, } n(\%)^{\mathrm{b}}\end{array}$} \\
\hline$<1$ year & $149(80.5)$ \\
\hline 1 year to $<5$ years & $28(15.1)$ \\
\hline$\geq 5$ years & $8(4.3)$ \\
\hline \multicolumn{2}{|l|}{$\begin{array}{l}\text { Specialty of physician who } \\
\text { diagnosed PHN, } n(\%)^{\mathrm{c}}\end{array}$} \\
\hline Dermatologist & $94(49.5)$ \\
\hline Pain specialist & $55(28.9)$ \\
\hline Neurologist & $35(18.4)$ \\
\hline Other & $6(3.2)$ \\
\hline \multicolumn{2}{|l|}{$\begin{array}{l}\text { How patient was diagnosed } \\
\text { with } \mathrm{PHN}, n(\%)\end{array}$} \\
\hline $\begin{array}{l}\text { Diagnosed by reporting } \\
\text { physician }\end{array}$ & $382(46.1)$ \\
\hline $\begin{array}{l}\text { Referred to reporting physician } \\
\text { from within hospital without } \\
\text { diagnosis }\end{array}$ & $49(5.9)$ \\
\hline $\begin{array}{l}\text { Referred to reporting physician } \\
\text { from within hospital with } \\
\text { diagnosis already }\end{array}$ & $141(17.0)$ \\
\hline $\begin{array}{l}\text { Referred to reporting physician } \\
\text { from outside hospital without } \\
\text { diagnosis }\end{array}$ & $51(6.2)$ \\
\hline $\begin{array}{l}\text { Referred to reporting physician } \\
\text { from outside hospital with } \\
\text { diagnosis already }\end{array}$ & $204(24.6)$ \\
\hline \multicolumn{2}{|l|}{$\begin{array}{l}\text { Method used for diagnosing } \\
\text { PHN, } n(\%)\end{array}$} \\
\hline Patient description & $736(88.9)$ \\
\hline Clinical examination & $682(82.4)$ \\
\hline Other & $13(1.6)$ \\
\hline
\end{tabular}

Table 4 continued

\begin{tabular}{ll}
\hline Clinical characteristic & $\begin{array}{l}\text { Patients diagnosed } \\
\text { with PHN }(\boldsymbol{n}=\mathbf{8 2 8})\end{array}$ \\
\hline $\begin{array}{l}\text { How patient presented with } \\
\text { rash and pain, } n(\%)\end{array}$ & $286(34.5)$ \\
Rash followed by pain & $262(31.6)$ \\
Pain followed by rash & \\
(prodromal pain of HZ) & \\
Rash and pain at the same time & $244(29.5)$ \\
Not documented & $35(4.2)$ \\
$\begin{array}{l}\text { Length of time in years between } \\
\text { presentation of rash and }\end{array}$ & \\
occurrence of pain, mean \\
(95\% CI)
\end{tabular}

The total number of patients may not sum to 828 for each characteristic because of missing data or because multiple answers could be given to a single question

$C I$ confidence interval, $H Z$ herpes zoster, $P H N$ postherpetic neuralgia

a Data available for 243 patients

b Data available for 185 patients

c Data available for 190 patients

widely, and the occurrence of PHN was dependent not only on the age of the patient sample but also the definition of PHN used [8]. Methodological issues such as study design and geographic location (e.g., rural vs. urban) may also be important.

The occurrence of PHN in patients with $\mathrm{HZ}$ also agrees with a systematic review of global HZ and PHN epidemiology, including studies from North and South America, Europe, the Middle East, as well as the Asia-Pacific region, where rates ranged from 5\% to 30\% [3]. These authors also noted that reported rates were dependent on not only the ages of the patient sample and the definition of PHN used, but also the type of study.

Results from studies with similar designs to the current study have been reported globally 
[32-35]. A rate of PHN at 1 month of $\sim 30 \%$ was reported in patients with $\mathrm{HZ}$ aged $\geq 60$ years in a study conducted by dermatologists and internists at 14 centers in Kushiro, Hokkaido, Japan [32]. In a separate study, the reported rate of PHN at 1 month was $47.6 \%$ in patients aged $>14$ years with $\mathrm{HZ}$ attending rural, urban, and semi-urban general practitioner (GP) offices in the autonomous community of Valencia, Spain [33]. A third study in the district of Pescara, Italy reported a rate of $\mathrm{PHN}$ at 1 month of $51.2 \%$ in patients, irrespective of age, attending GP offices and one urban hospital [34]. Finally, a study in four regions of Italy reported a rate of $\mathrm{PHN}$ at 1 month of $22.7 \%$ in patients aged $>50$ years attending GP offices [35]. Notably, although these studies were of similar, but not identical, design to the current study, there was considerable variability in the occurrence of PHN compared with the current study.

Approximately three-quarters of patients with PHN had comorbidities. The most common comorbidities were hypertension and diabetes (type 1 or type 2). This is in agreement with a recent systematic review of $\mathrm{HZ}$ and $\mathrm{PHN}$ epidemiology across the Asia-Pacific region [8], where hypertension (range 4.0-32.1\%) and diabetes $(2.5-20.6 \%)$ were also the most common comorbidities, although the rates in the current study were toward the upper limits of those ranges. In a hospital-based study in China [36], hypertension and diabetes were again the most common comorbidities, but rates were somewhat lower than those in the current study (22.2\% and $11.7 \%$, respectively). Differences in study design may be responsible for this discrepancy, specifically the fact that patients were seeking hospital-based medical care in the current study.

The current prevalence of $\mathrm{HZ}$, and subsequently PHN, in China and across the AsiaPacific region may be expected to be influenced by the availability of effective vaccines [25]. The Advisory Committee on Immunization Practices recommends vaccination against $\mathrm{HZ}$ in immunocompetent adults aged $\geq 50$ years [37]. However, vaccination has not become routine practice in the Asia-Pacific region-in part because preventive adult healthcare, including adult immunization, is not given high priority and also because of a paucity of epidemiological evidence [8]. The prevalence data reported in this study provide epidemiological evidence that could help inform government and policymakers when making decisions about the assessment and management of $\mathrm{HZ}$ and $\mathrm{PHN}$ [25].

This study has several limitations. The population sample consisted only of patients presenting for medical care to 24 hospitals in seven cities. The findings may not, therefore, be generalizable to the wider population, for instance those individuals with $\mathrm{HZ}$ and/or PHN who live in rural areas, who live in other Chinese cities, or who do not regularly present to hospitals for medical care. Cross-sectional studies also have inherent limitations, including the inability to measure incidence (only prevalence) and susceptibility to bias due to low response rates [29]. In addition, although different types of PHN exist, this study was not designed to capture these subtypes. To gain further insights into the epidemiology of $\mathrm{HZ}$ and PHN in China, further studies could include broader populations; for example, including individuals who live in rural or mixed rural/urban areas. The aim of this study was to estimate the prevalence of $\mathrm{HZ}$ and PHN in China, and to examine the clinical characteristics of patients identified with PHN. While for this purpose the data are descriptive only, we encourage other researchers to formulate hypotheses involving statistical comparisons that would advance the current research.

\section{CONCLUSION}

This epidemiological cross-sectional study in hospital-based sites across seven different Tier 1 and Tier 2 Chinese cities reported a prevalence of $\mathrm{HZ}$ and $\mathrm{PHN}$ of $7.7 \%$ and $2.3 \%$, respectively. Of those patients with HZ, 29.8\% had PHN. Rates of $\mathrm{HZ}$ and $\mathrm{PHN}$ increased with age, and were highest in those aged $\geq 70$ years. These results provide a current estimate of the prevalence of $\mathrm{HZ}$ and $\mathrm{PHN}$ in adults aged $\geq 40$ years in urban China. The prevalence rates of $\mathrm{HZ}$ and PHN reported here are similar to previously 
reported rates in China and worldwide, and further highlight the global nature of $\mathrm{HZ}$ and PHN.

\section{ACKNOWLEDGEMENTS}

We thank all the physicians who participated in this study. We thank Dr. Ruoyu Li of Peking University First Hospital, Beijing, China for comments on a previous version of this manuscript.

Funding. This study and the article processing fees were funded by Pfizer Inc. All authors had full access to all of the data in this study and take complete responsibility for the integrity of the data and accuracy of the data analysis.

Medical Writing Assistance. Medical writing support was provided by David Cope, PhD, of Engage Scientific Solutions, and funded by Pfizer.

Authorship. All named authors meet the International Committee of Medical Journal Editors (ICMJE) criteria for authorship for this article, take responsibility for the integrity of the work as a whole, and have given their approval for this version to be published.

Prior Presentations. Some of the data in this manuscript were presented at the 13th annual academic conference of the Chinese Society of Pain Management, Chinese Medical Association, 2017.

Disclosures. Marco DiBonaventura is an employee of Pfizer, and has stock, or stock options, with Pfizer. Markay Hopps is an employee of Pfizer, and has stock, or stock options, with Pfizer. Patrick Hlavacek is an employee of Pfizer, and has stock, or stock options, with Pfizer. Joseph C. Cappelleri is an employee of Pfizer, and has stock, or stock options, with Pfizer. Alesia Sadosky is an employee of Pfizer, and has stock, or stock options, with Pfizer. Bruce Parsons is an employee of Pfizer, and has stock, or stock options, with Pfizer. Margarita Udall is an employee of Pfizer, and has stock, or stock options, with Pfizer. Yu Xuan Chen was an employee of Pfizer, and had stock, or stock options, with Pfizer from July 2016 to January 2018, a time-period covering the initiation and completion of this study. Fei Yang, Shengyuan $\mathrm{Yu}$, Bifa Fan, Yanqing Liu, Ian Kudel, and Kristen Concialdi have nothing to disclose.

Compliance with Ethics Guidelines. This study was conducted in accordance with legal and regulatory requirements and accepted research practices described in the Good Practices for Outcomes Research issued by the International Society for Pharmacoeconomics and Outcomes Research. The final protocol and any amendments were reviewed and approved by the Ethics Committee at Chinese PLA General Hospital, Hai Dian District, Beijing. As this was a retrospective epidemiological study, patient consent was not required.

Data Availability. The data sets generated and analyzed during the current study are available from the corresponding author on reasonable request.

Open Access. This article is distributed under the terms of the Creative Commons Attribution-NonCommercial 4.0 International License (http://creativecommons.org/licenses/ by-nc/4.0/), which permits any noncommercial use, distribution, and reproduction in any medium, provided you give appropriate credit to the original author(s) and the source, provide a link to the Creative Commons license, and indicate if changes were made.

\section{REFERENCES}

1. Johnson RW, Rice AS. Clinical practice. Postherpetic neuralgia. N Engl J Med. 2014;371:1526-33.

2. John AR, Canaday DH. Herpes zoster in the older adult. Infect Dis Clin North Am. 2017;31:811-26.

3. Kawai K, Gebremeskel BG, Acosta CJ. Systematic review of incidence and complications of herpes 
zoster: towards a global perspective. BMJ Open. 2014;4:e004833.

4. Kawai K, Yawn BP. Risk factors for herpes zoster: a systematic review and meta-analysis. Mayo Clin Proc. 2017;92:1806-21.

5. Insinga RP, Itzler RF, Pellissier JM, Saddier P, Nikas AA. The incidence of herpes zoster in a United States administrative database. J Gen Intern Med. 2005;20:748-53.

6. Yawn BP, Saddier P, Wollan PC, St Sauver JL, Kurland MJ, Sy LS. A population-based study of the incidence and complication rates of herpes zoster before zoster vaccine introduction. Mayo Clin Proc. 2007;82:1341-9.

7. Gauthier A, Breuer J, Carrington D, Martin M, Rémy $\mathrm{V}$. Epidemiology and cost of herpes zoster and postherpetic neuralgia in the United Kingdom. Epidemiol Infect. 2009;137:38-47.

8. Chen LK, Arai H, Chen LY, et al. Looking back to move forward: a twenty-year audit of herpes zoster in Asia-Pacific. BMC Infect Dis. 2017;17:213.

9. Stein AN, Britt H, Harrison C, Conway EL, Cunningham A, Macintyre CR. Herpes zoster burden of illness and health care resource utilisation in the Australian population aged 50 years and older. Vaccine. 2009;27:520-9.

10. Jih JS, Chen YJ, Lin MW, et al. Epidemiological features and costs of herpes zoster in Taiwan: a national study 2000 to 2006. Acta Derm Venereol. 2009;89:612-6.

11. Lin YH, Huang LM, Chang IS, et al. Disease burden and epidemiology of herpes zoster in pre-vaccine Taiwan. Vaccine. 2010;28:1217-20.

12. Chao DY, Chien YZ, Yeh YP, Hsu PS, Lian IB. The incidence of varicella and herpes zoster in Taiwan during a period of increasing varicella vaccine coverage, 2000-2008. Epidemiol Infect. 2012;140:1131-40.

13. Park SY, Kim JY, Kim CD, Kim CW, Lee KS. A clinical study on herpes zoster during the last 10-yearperiod (1994-2003). Korean J Dermatol. 2004;42:1531-5.

14. Choi WS, Noh JY, Huh JY, et al. Disease burden of herpes zoster in Korea. J Clin Virol. 2010;47:325-9.

15. Toyama N, Shiraki K, Society of the Miyazaki Prefecture Dermatologists. Epidemiology of herpes zoster and its relationship to varicella in Japan: a 10-year survey of 48,388 herpes zoster cases in Miyazaki prefecture. J Med Virol. 2009;81:2053-8.
16. Tsai T-F, Yu H-S, Rampakakis E, et al. Assessment of burden of illness due to herpes zoster and predictors of outcomes in Taiwan: a prospective observational study. Int J Infect Dis. 2012;16:e115.

17. Cho SI, Lee CH, Park GH, Park CW, Kim HO. Use of S-LANSS, a tool for screening neuropathic pain, for predicting postherpetic neuralgia in patients after acute herpes zoster events: a single-center, 12-month, prospective cohort study. J Pain. 2014;15:149-56.

18. Kurokawa I, Kumano K, Murakawa K, Hyogo Prefectural PHN Study Group. Clinical correlates of prolonged pain in Japanese patients with acute herpes zoster. J Int Med Res. 2002;30:56-65.

19. Kanbayashi Y, Onishi K, Fukazawa K, et al. Predictive factors for postherpetic neuralgia using ordered logistic regression analysis. Clin J Pain. 2012;28:712-4.

20. Tunsuriyawong S, Puavilai S. Herpes zoster, clinical course and associated diseases: a 5-year retrospective study at Ramathibodi Hospital. J Med Assoc Thai. 2005;88:678-81.

21. Aunhachoke K, Bussaratid V, Chirachanakul P, et al. Measuring herpes zoster, zoster-associated pain, post-herpetic neuralgia-associated loss of quality of life, and healthcare utilization and costs in Thailand. Int J Dermatol. 2011;50:428-35.

22. Goh CL, Khoo L. A retrospective study of the clinical presentation and outcome of herpes zoster in a tertiary dermatology outpatient referral clinic. Int J Dermatol. 1997;36:667-72.

23. Chaudhary SD, Dashore A, Pahwa US. A clinicoepidemiologic profile of herpes zoster in North India. Indian J Dermatol Venereol Leprol. 1987;53:213-6.

24. Abdul Latheef EN, Pavithran K. Herpes zoster: a clinical study in 205 patients. Indian J Dermatol. 2011;56:529-32.

25. Zhu Q, Zheng $\mathrm{H}, \mathrm{Qu} \mathrm{H}$, et al. Epidemiology of herpes zoster among adults aged 50 and above in Guangdong, China. Hum Vaccin Immunother. 2015;11:2113-8.

26. Li Y, An Z, Yin D, et al. Disease burden due to herpes zoster among population aged $\geq 50$ years old in China: a community based retrospective survey. PLoS One. 2016;11:e0152660.

27. Lu L, Suo L, Li J, Pang X. A retrospective survey on herpes zoster disease burden and characteristics in Beijing, China. Hum Vaccin Immunother. 2018;14:2632-5. 
28. Song T. Statistical analysis of 522 cases of patient with herpes zoster. Med J Wuhan Univ. 2002;23:379-82.

29. Hennekens $\mathrm{CH}$, Buring JE. Epidemiology in medicine. Philadelphia: Lippincott Williams and Wilkins; 1987. p. 400.

30. Berger ML, Sox H, Willke RJ, et al. Good practices for real-world data studies of treatment and/or comparative effectiveness: recommendations from the joint ISPOR-ISPE Special Task Force on RealWorld Evidence in Health Care Decision Making. Value Health. 2017;20:1003-8.

31. Yu S, Wan Y, Wan Q, et al. [Chinese expert consensus on diagnosis and treatment of postherpetic neuralgia]. Chin J Pain Med. 2016;22:161-7.

32. Sato K, Adachi K, Nakamura $H$, et al. Burden of herpes zoster and postherpetic neuralgia in Japanese adults 60 years of age or older: results from an observational, prospective, physician practicebased cohort study. J Dermatol. 2017;44:414-22.

33. Cebrian-Cuenca AM, Díez-Domingo J, San-MartínRodríguez M, Puig-Barberá J, Navarro-Pérez J,
Herpes Zoster Research Group of the Valencian Community. Epidemiology and cost of herpes zoster and postherpetic neuralgia among patients treated in primary care centres in the Valencian community of Spain. BMC Infect Dis. 2011;11:302.

34. Parruti G, Tontodonati M, Rebuzzi C, et al. Predictors of pain intensity and persistence in a prospective Italian cohort of patients with herpes zoster: relevance of smoking, trauma and antiviral therapy. BMC Med. 2010;8:58.

35. Alicino C, Trucchi C, Paganino C, et al. Incidence of herpes zoster and post-herpetic neuralgia in Italy: results from a 3-years population-based study. Hum Vaccin Immunother. 2017;13:399-404.

36. Yuan LL, Wang LX, Xie YM, et al. [Analysis on clinical features and treatment of herpes zoster patients hospitalized in real world]. Zhongguo Zhong Yao Za Zhi. 2014;39:3469-73.

37. Dooling KL, Guo A, Patel M, et al. Recommendations of the Advisory Committee on Immunization Practices for use of herpes zoster vaccines. MMWR Morb Mortal Wkly Rep. 2018;67:103-8. 